\title{
Sociological Approaches to the Pop Music Phenomenon
}

\author{
PAUL M. HIRSCH \\ University of Michigan
}

Social scientists have long theorized about "mass society" and "mass culture" and, generally, are appalled by the frightening images brought to mind by these concepts. A wide-ranging debate over their validity, a concern about the "functions" of the mass media in modern society, and their "effects" on the general public have been major subjects of mass communications research for the last two decades. ${ }^{1}$ Studies of popular entertainment too often are based exclusively on these concerns.

American mass entertainment has undergone an extraordinary set of transformations in recent years. Several revolutions in communications technology, shifts in program content, altered audience composition, and public opinion have received widespread attention. A related transformation, less widely discussed, has occurred in the organization of mass entertainment. Today's entertainment industries bear little resemblance to their namesakes of twenty years ago.

This paper will discuss four sociological approaches to the study of popular culture and relate each to a set of radical changes that have

Author's Note: This paper is part of an ongoing study of changing popular song styles, adolescents' musical taste preferences, and the structure of the pop music industry conducted at the Survey Research Center, University 
occurred in American popular music since the early 1950s. I will argue that the fragmented and disordered state of systematic research in this area is at least partly due to the failure of sociologists to integrate these several approaches; and that an adequate understanding of our changing popular culture in general-and of the "rock revolution" in particular-will require studies of the organization of the industries involved, the impact of technological change upon their output, as well as studies of their content and sociological and psychological effects. In the sections to follow, we will examine briefly (1) content analyses and the functional approach to the mass media, (2) the impact of popular music on its audience, (3) the impact of technological change on mass media programming, and (4) organizational analysis of entertainment industries.

\section{CONTENT ANALYSES AND THE FUNCTIONAL APPROACH TO THE MASS MEDIA}

The content of mass media programming has been analyzed periodically in professional journals since the early 1940s. Whatever the medium, be it magazine stories (Johns-Heine and Gerth, 1949; Berelson and Salter, 1946), movie themes (Kracauer, 1949; Wolfenstein and Leites, 1950), popular songs, television serials (Arnheim, 1949), or comic strips (Auster, 1954), a single conclusion has emerged consistently: controversial subjects are avoided, and an idealized set of traditional values are reinforced.

Popular songs produced by Tin Pan Alley have always been notorious for their single-minded devotion to lyrics about "moon and June," to the virtual exclusion of all other topics. In 1944, Peatman reported that practically all popular tunes fell into three categories: "happy in love," "sad in love," and "novelty songs with sex interest." In 1957, Horton found that song lyrics had changed very little since the earlier study. Eighty-seven percent of popular song lyrics still pertained to the "drama of courtship" (Horton, 1957). The remaining thirteen percent:

of Michigan, under the direction of Dr. Stephen B. Withey. I wish to thank Dr. John Robinson for generously permitting me to paraphrase our joint research and Dr. Withey for comments on an earlier version of this paper, presented at the 1970 meetings of the International Communications Association. Funds for this project were provided by NIMH Grant 1 RO 1 MH17064-01. 
range widely and show no clear-cut focus. They include song dances, general narrative ballads on love themes, religious songs, comic songs, and others that could not be classified [Carey, 1969: 730].

These findings bore out Hayakawa's (1955) critique in "Popular Songs Versus the Facts of Life" and supported the sociological consensus that mass entertainment and mass media programming serve to reinforce conventional morality, play a small role in motivating individuals toward organized social action, and present their audiences with a continuous flow of standardized trivia. Many critics have condemned such programming for failing to educate or uplift its followers or for encouraging escapism and a form of false consciousness. Others have defended it as harmless in its effects and democratic in providing audiences with the entertainment which ratings and box office receipts have shown they like best. ${ }^{2}$

\section{The Changing American Popular Song}

Until recently, a single conclusion on which nearly all observers could agree, based on their content analyses of mass media programs, was that popular culture supports prevailing norms, that it is either an agent of social control or epiphenomenal in its impact. This conclusion has been challenged increasingly since the early 1960s. Movie themes (Gans, 1964), large-circulation magazine articles and stories (Brown, 1968; Friedrich, 1969), and, in particular, popular song lyrics can no longer be said, without substantial qualification, to either (a) reflect the dominant values of American society or (b) direct their appeal to the broadest markets available-i.e., to what is generally called the "lowest common denominator." By 1966, only seventy percent of popular song hits concerned stages in the courtship process (Carey, 1969). The remaining songs' lyrics reveal more specific concerns: the role of the individual in the conventional world has become a crucial issue. "Will he become part of the conventional world or will he drop out and create his own scene? The decision to do something about one's life, to think for one's self, no matter what the consequences, is generally enjoined"' (Carey, 1969: 730).

\section{"Social Protest" Hits}

More specifically, a rising proportion of best-selling popular songs contain lyrics that comment on controversial subjects previously avoided by songwriters. Increasingly, song lyrics have come to call Establishment norms into question and, implicitly or explicitly, to sanction alternative 
courses of action. (This shift in content has been demonstrated by Carey, 1969; Mooney, 1968; Cole, 1970; Peterson and Berger, 1967; and McLaughlin, 1968.) Whereas Horton (1957) found only thirteen percent of popular songs unrelated to courtship patterns, Carey reported, in 1969, that the proportion had more than doubled to thirty percent. Many of these hit songs contained lyrics which condemned war, acknowledged drug use, or otherwise challenged the status quo. The pattern of courtship, idealized in the remaining seventy percent, is no longer one to which a majority of adults would likely subscribe (e.g., it is more physical, less romantic, less permanent).

A number of writers (Robinson and Hirsch, 1969a, and 1969b; Denisoff and Levine, 1969; and Cole, 1970) have categorized as social protest all hit songs whose lyrics are concerned with controversial themes surrounding the morality of war, relations between different racial groups, drug usage, and also any songs whose lyrics are critical of widely accepted values or legitimized roles in American society. Several examples of popular songs with social protest lyrics are:

Itemize the things you covet

As you squander through your life,

Bigger cars, bigger houses,

Term insurance for your wife,

Tuesday evenings with your harlot

And on Wednesdays it's your charlatan analyst

He's high up on your list

You better take care of business, Mr. Businessman.

[Mr. Businessman recorded by Ray Stevens] ${ }^{3}$

Yes it's true I am a young man

But I'm old enough to kill

I don't want to kill nobody

But I must if you so will

All I know is that I'm young

And your rules, they are old

If I've got to kill to live

Then there's something left untold

It's the rules, not the soldiers

That are my real enemy

$2+2$ in on my mind.

$[2+2 \text { recorded by Bob Seger }]^{4}$

Leave your cares behind

Come with us and find

The pleasures of a journey to the center of the mind 
But please realize you'll probably be surprised

For it's a land unknown to man

Where fantasy is fact

So if you can please understand

You might not come back

Take a ride to the land inside and you'll see

How happy life could be.

[Journey to the Center of the Mind recorded by the Amboy Dukes] ${ }^{5}$

Listen to the children while they play,

Now ain't it kind of funny what the children say,

Cheat on your taxes, don't be a fool,

Now what was that you said about a golden rule?

Never mind the rule, just play to win

And hate your neighbor for the shade of his skin,

Stab him in the back is the name of the game,

And mommy and daddy are who's to blame,

Skip a rope.

[Skip a Rope recorded by Hensen Cargill] ${ }^{6}$

Hit protest songs such as these, which hurl challenges at conventional political and moral beliefs, have engendered strong reactions, much like the public outcry that has greeted a number of X-rated motion pictures. Most recently, for example, Art Linkletter, after testifying before a congressional committee on drug abuse, singled out the popular music industry for encouraging youngsters to experiment with illegal drugs:
Almost every time a top 40 record is played on the radio, it is an ad for acid, marijuana, and trips. The lyrics of the popular songs and the jackets on the albums ... are all a complete, total campaign for the fun and thrill of trips [New York Times, 1969].

In May 1967, Billboard magazine reported that Gordon McClendon, president of a chain of (nonrock) radio and television stations, had instituted a panel of "prostitutes, ex-prostitutes, junkies, and ex-junkies to assist in weeding out suggestive records ... in his campaign against 'filth' in the record industry." He stated:

We've had all we can stand of the record industry's glorifying marijuana, LSD, and sexual activity. The newest Beatles record has a line of 40,000 purple hearts in one arm. Is that what you want your children to listen to? ... [I call for] a rather updated version of the Boston Tea Party. I suppose you might 
call it the Wax Party-one in which all the distasteful records which deal with sex, sin, and drugs [would be purged from radio air-play].

It should be noted the Top 40 stations generally boycotted the Beatles' record referred to by McClendon, and, by any reasonable standard, Linkletter exaggerated strongly the extent to which records aired by Top 40 stations contain references to drugs. It is equally clear, however, that a significant change has taken place in American popular music: unconventional messages about sex, drugs, and politics are recorded routinely now by major record companies and disseminated by widely listened-to radio stations across the land. Few would have predicted this development as recently as 1960 . In an era of "message" films and "progressive rock," movies, popular records, and radio broadcasting no longer can be characterized in functional terms simply as escapist agents of social control. Today, this description is better illustrated by the programming of commerical television networks.

Theories about the social functions served by the media are rooted empirically in analyses of mass media articles and program content. A shift in the direction of the messages transmitted is assumed to induce, or reflect, attitudinal changes on the part of the audience. One inference drawn readily from content analyses is that the themes abstracted by the researcher are the same ones perceived by the audience. A typical example of this inferential leap appears in Carey's article (1969: 722), where, despite admirable qualifications elsewhere in the text, it is suggested that observed changes in content signify, a priori, a "dramatic shift in the value preferences of young people." That this inference may not be justified is a general finding of investigators working in the second traditional approach to mass communications research, students of the impact, or the effects, of the mass media on the general population.

\section{THE IMPACT OF POPULAR MUSIC ON ITS AUDIENCE}

Many analysts and observers of the popular music scene seem to subscribe to all or part of a "hypodermic needle" theory of song lyrics' effects. It is assumed that (implied or explicit) values expressed in popular hit protest songs are (a) clear to a majority of listeners, (b) subscribed to by a large proportion of listeners, and (c) likely to influence the attitudes and behavior of the uncommitted. The theory further assumes a "direct hit" for messages broadcast by the electronic media and directed at an undifferentiated target audience. None of these assumptions has ever been 
tested empirically: Are song lyrics purely epiphenomenal, or can they be taken as reliable indicators or determinants of teenagers' values?

The hypodermic needle theory has persisted despite the finding of Katz and Lazarsfeld (1955) and others that seemingly straightforward information is perceived differently by individual receptors, for whom it is filtered and interpreted by opinion leaders and informal associates. In the case of rock-and-roll songs, the message contained in the lyrics frequently is obscure, rather than straightforward. Lyrics, generally, are treated by performers as but one of several components of the total sound. Consequently, they must be abstracted from accompanying complex vocal and instrumental arrangements (which often tend to drown out the words) by a special effort on the part of the listener. Once the lyrics are deciphered, their meaning may appear ambiguous or confusing. Teenagers may not impute the same meanings to a song's words as do social researchers and critics. As we shall see, they tend to be unaware of many songs' lyrics and messages: Most teenagers are attracted to popular records more by their overall sound and beat-or the performing group-than by their verbal content (Robinson and Hirsch, 1969a, 1969b). Systematic social research has yet to demonstrate any effects of popular song lyrics upon their listeners.

Beyond the number of copies a record sells and the age groups to which it appeals, there is very little published information available about record consumers. We do know that the median age of consumers of hit singles has been decreasing steadily since the early 1950s, hence it is very probable that the audience for popular music today is younger than its counterpart of fifteen or more years ago (New York Times, 1967; Record Industry Association of America, 1964). Studies of Americans' musical taste also have found that favorite types of music and social background are highly associated (Schuessler, 1948; Coleman, 1961; Brunswick, 1962). But sociologists only recently have begun to investigate questions such as: Are all Top 40 records purchased by the same population, or do certain popular song styles appeal disproportionately to particular groups? Are records containing deviant messages primarily purchased for the content of their lyrics, or is it the sound and beat of the rendition that appeals to their buyers? How closely can musical taste preferences be predicted from a knowledge of background variables?

\section{Findings by Robinson and Hirsch}

Several studies of tenagers' song style preferences have been conducted by Robinson and Hirsch to get at preliminary answers to these questions. 
Four surveys of high school students in Michigan were completed under Robinson's direction, and two national samples are in the analysis stage. Between Fall 1967 and Winter 1969, approximately 1,200 high school students in Detroit, Flint, and Grand Rapids, Michigan, filled out a confidential questionnaire on their attitudes toward popular songs in general and current popular social protest hist in particular. A number of surprises emerged from these data. Findings from the first two Michigan surveys were reported in detail by Robinson and Hirsch (1969a). In brief, these included:

(1) The universal popularity of "current popular hits" across the entire sample. Only one percent expressed a dislike for popular hits. In this sense, teenagers do constitute a "homogeneous" audience for this type of music.

(2) Each respondent was asked to list his "three favorite records." These were coded into one of four "song style" categories: "rhythm and blues (soul) hits," "social protest hits," "other hits," and "square." All named songs on the popular record "charts" were coded into one of the first three categories. Any record named which was never on the hit parade was placed in the residual, "square" category. Ninety-three percent of all records listed were popular song hits.

Respondents' song style preferences within the category "current popular hits" were found to vary markedly by race and social class. Students listing "protest hits" were disproportionately $(2: 1)$ from white middle-class homes; students listing "other hits" were disproportionately $(2: 1)$ from white lower-class backgrounds; and teenagers listing "rhythm and blues hits" were overwhelmingly Negro $(8: 1)$. Age, sex, grades in school, and number of friends enumerated failed to predict well the popular song style preference. There was little overlap or crossover of song style preferences among the three records listed by each respondent.

(3) Fewer than thirty percent were able to write out correctly the "message" allegedly contained in four controversial hit "protest" song lyrics. Our coding of "correct interpretations" was based primarily on the explanation of a given song's meaning presented in the popular press. For example, we coded any reference to "LSD" as "correct" for the song, "Lucy in the Sky with $D$ iamonds," on the basis of widely circulated accounts in the press that this was its "message"; a denial by the Beatles that this was their intent was thus ignored. In some instances we took what we considered an obvious interpretation as the "correct" one (e.g., our coding of the 
song, "Mr. Businessman," cited earlier, as a social protest hit. For further discussion of the songs selected and coding procedures employed in defining "messages" and song styles, see Robinson and Hirsch (1969a).

Correct interpretations ranged from ten to thirty percent, depending on the particular song in question. A "selective listening" phenomenon was noted, wherein many students appear unaware of certain songs played over their favorite radio station-they are "tuned in" only to selections in the style with which their background characteristics are associated. In place of the expected lowest common denominator (homogeneous) audience, we found the audience heterogeneous, stratified by social class and song style preference. When asked directly if a song's attraction lies in its sound or its meaning seventy percent responded that they are more attracted by a song's sound. These data strongly suggest that a majority of teenagers fail to perceive the "deviant" messages contained in a number of hit social protest songs.

Thus, while nearly all teenagers followed current popular hits, there was much patterned variation within this musical category. Listeners to Top 40 radio stations did not constitute a single audience. Rather, the composite audience broke down into stratified social groups, each of which listened selectively for the air-play of the popular song style with which it was associated. To generalize from our surveys, we will assume that these findings (a) are not specific to two cities in the Midwest; (b) would be replicated in smaples of persons over 17 years of age; and (c) have not been affected significantly by the introduction of "progressive rock" formats by FM radio stations in most major cities. (We are presently testing each of these assumptions with data from two national samples).

If certain popular song styles appeal disproportionately to particular subgroups within the American teenage population, it follows that all Top 40 or rock-and-roll records are not interchangeable in the eyes of young consumers. The stratified teenage audience (usually viewed by adults as an undifferentiated horde) is an aggregate of individuals who form distinct popular music subaudiences--for protest hits, or other hits, or rhythm and blues hits-with little crossover in membership. As radio station formats become more specialized, each subaudience is turning to speciality programming that features just one popular music style, rather than the more usual Top 40 potpourri. Thus, progressive rock stations, featuring primarily what we have labeled "protest hits," have drawn their audience almost exclusively from well-to-do high school and college students who 
formerly listened to all-purpose Top 40 stations. Blacks attend to soul-formatted rather than Top 40 stations whenever a choice is available (Robinson and Hirsch, 1969b); and white Southern teenagers probably are disproportionately receptive to all-country stations. The Top 40 format, still featuring the something-for-everyone-in-the-pop-music audience formula, thus, faces increasing competition. Paradoxically, this will encourage cultural pluralism in the aggregate but, simultaneously, will increase the cultural isolation of each audience subculture.

We have, so far, examined two sociological approaches to the study of popular music in the United States. First, the content analysis approach showed that popular song lyrics have changed radically during the last fifteen years. However, our second approach to the pop music phenomenon-the study of songs' impact on listeners and consumers-suggested that caution be exercised before attributing too much of the change in musical message content to a dramatic shift in the values of young people. We saw, for example, that the vast majority of teenagers sampled in two Michigan cities, including those attracted by the social protest song style, were unable to interpret the messages these records allegedly contained in the same terms as research scholars and social critics. That is, most teenagers made no reference to drugs, sex, or politics when asked to interpret the meanings of songs which we believed said a great deal about each of these subjects (Robinson and Hirsch, 1969b).

A third and fourth approach to the study of popular culture provide a new perspective which should aid in explaining the changes observed in popular music.

\section{THE IMPACT OF TECHNOLOGICAL CHANGE ON MASS MEDIA CONTENT}

As each new technologically advanced mass medium appears, it tends to take over the functions served by an earlier medium, forcing the latter to redefine its role. This is essentially what happened to radio with the advent of television. The resultant competition that developed between them threatened radio's existence to such an extent that it had to seek new and different markets which could complement those of television. The movie industry was affected similarly. Radio and movie formats have since undergone a series of rapid changes in their attempts to maintain an audience in the face of television's better capacity to provide superior mass entertainment. 
Rock-and-roll radio emerged in the fifties as part of the radio industry's confused response to the onslaught of television. Network programming, directed at the largest possible cross-section of listeners, was replaced by formats directed at subcultural markets-i.e., small aggregates of listeners previously neglected because their numbers could not equal the size required by the logic of network programming (Gans, 1961; Hirsch, 1969). All-news, all-country, all-Top 40, all-soul, and all-underground stations are each a successful illustration of this strategy of slicing up the total radio audience into subcultural groupings interested in a single specialty broadcast format. Movies adopted a similar strategy when they opted for problem films (Gans, 1964): the hitherto cross-sectional mass audience was divided into its constituent parts.

American youth, thus, was provided a medium all its own as the accidental by-product of a revolution in communications technology and its economic consequences. The age structure of our population encouraged special programming directed at the youth audience. Young people became increasingly numerous and prosperous at the same time that radio was forced into subcultural markets. The postwar baby boom was growing up and represented substantial purchasing power ( $\$ 10$ billion by 1959 ; over $\$ 25$ billion today). Top 40 radio was tried on an experimental basis and proved to be highly successful.

\section{The Top 40 Format}

The Top 40 format combines all popular song styles and continuously broadcasts a repetitive selection of thirty to forty records per week. Most of these are played for several weeks before being dropped from the playlist. A limited number of soul, country, protest, oldie, and other hits are thrown together into a preset mix, which is designed to include something for everyone in the mass audience for popular music. Top 40 hit records are identifiable very often only by their common characteristic of having all been selected (somewhat arbitrarily) for air-play by Top 40 radio station programmers.

For example, performers like the Beatles or the Rolling Stones are associated directly with the term "rock-and-roll" because their records were heard first over Top 40 radio stations. Other singers' records often obtain air-play initially from non-Top 40 programs but are "coopted" onto the Top 40 playlist at a later date and thus exposed to the larger mass audience. Upon the selection of his record(s) by Top 40 stations, a singer is transformed overnight from a relative unknown into a "rock star." 
Performers whose records have "crossed over" in this fashion include the late Janis Joplin, Bob Dylan, James Brown, Country Joe and the Fish, and-earlier in her career-Barbra Streisand. Since all records selected by Top 40 station program directors are thereby conferred the status of rock records the musical style sometimes cannot be defined independently of the radio stations over which the records are broadcast.

This observation applies equally well to the music industry's definition of "underground" popular hits. A growing number of records broadcast by radio stations featuring the "progressive rock" format appear to be unconcerned with political questions, drug usage, or other controversial issues. If a record is played first by an underground station, however, it is generally defined as underground throughout the industry-regardless of its message content-perhaps because it was found to appeal first to the underground audience.

The ascendance of television had a further impact on popular music. In record industry parlance, "air-play is the lifeline of any company." Before the widespread adoption of television, four major record companies sold 75\% of all hit records in the United States (Peterson and Berger, 1967). Their output was geared almost entirely to the program choices of network radio. When radio stations switched to subcultural programming, this "Big Four" were taken by surprise; they were unskilled at recording the musical styles that had been delegated for years to small entrepreneurs who catered primarily to the smaller subcultural markets.

\section{Unanticipated Consequences}

This brief overview of the impact of technological change on programming decisions in the mass media represents a third sociological approach to the study of popular culture. The widespread adoption of television, and the manner in which licenses were granted, led to a set of unanticipated consequences, of which rock-and-roll is but one example. This approach derives from the teachings of Merton (1936) and Ogburn (1964), whose perspectives on the analysis of social change should sensitize more sociologists to seek out unanticipated consequences of this type. In the present case, it is very doubtful that popular music could have changed as radically as we have seen were it not for the structural changes wrought by seemingly unrelated developments in mass communications technology.

The impact of technological change is closely associated with the fourth and last approach we will examine to the study of mass entertainment: the study of entertainment industries as organization sets. 


\section{ORGANIZATIONAL ANALYSIS OF ENTERTAINMENT INDUSTRIES}

The advent of the Top 40 radio format, and the instant popularity of the records it featured, fundamentally altered the character of the market at which pop records were directed. Long used to producing popular music for the mainstream American audience, the largest record companies were unable and, at first, unwilling to plunge into subcultural recording and marketing. A resultant vacuum was filled by eager small entrepreneurs. Singles (45 r.p.m.) cost only several hundred dollars to record and manufacture (Hirsch, 1969); the prospect of huge returns on such a small investment in a highly uncertain environment resulted in the establishment of many new record companies and a rise in the industry's output to over 300 new singles per week. Large record firms had not yet developed the type of personnel required to record the raucous sounds of rock-and-roll music. At first, they simply served as national distributers for rock records manufactured by smaller competitors.

All record companies were forced now to compete to an unprecedented degree for the exclusive right to record pop musicians and entertainers whose records were most likely to receive air-play. At the height of this free-for-all, in 1958, the "payola" scandals brought to light the fact that record companies were bribing radio station personnel to insure air-play for their new releases.

The organization and direction of American popular music were also affected by the outcome of a suit against the American Society of Composers, Authors, and Publishers (ASCAP) in 1941. Small entrepreneurs, songwriters, and musicians were aided considerably in their attempt to break into the recording field by a judgment striking down ASCAP's legal right to prevent the recording and broadcasting of songs composed by nonmember writers. Membership admissions had been restrictive and discriminatory (Mooney, 1968).

In order to retain sales leadership and to capture subcultural markets from increasingly aggressive competitors, the large record companies were forced to (1) purchase the contracts of up-and-coming artists from smaller companies (this is how Elvis Presley became associated with RCA Records, for example), and, more importantly, (2) undertake negotiations with the musicians and record producers, who were in an increasingly advantageous bargaining position vis-à-vis the record companies: (a) rock-and-roll tunes, unlike earlier popular songs, are composed generally by the same musicians who record them, hence it became more difficult for companies to select 
the songs to be recorded by the musicians; (b) the entry of more companies into this field created a "seller's market" (Gleason, 1969). The net result of these events within the industry was that performers were able to obtain an increasing amount of artistic control over the songs which they recorded and which were released by major record companies.

Many analysts attribute the daring and radical lyrics of some of today's hit songs to the desire of record companies to please, or to convert, their consumers. Scholars in the content analysis tradition and social critics tend to believe that the controversial lyrics of some current songs reflect or influence the attitudes of an overwhelming majority of young people. Much more attention should be focused on the companies' losses in bargaining power vis-à-vis the musicians and on the large-scale intrusion of musicians' values into the songs they record. Carey (1969: 723) reports that by 1966 ,

slightly over 65 percent of the songs (containing lyrics expressing the "new (protest) values" were written by members of the group which recorded them. Lyrics which are not rock and roll, those celebrating older, more conventional values, were characteristically not written by the groups which recorded them. Only 13 percent of this type of lyrics were written by the groups which sang them.

The intrusion of a new set of values into popular songs composed by the groups which record and perform them is clear from the content analyses reviewed earlier. It seems equally clear, however, that a majority of teenage listeners and consumers are unaware of the messages conveyed by these songs and are generally indifferent (Robinson and Hirsch, 1969a, 1969b; Denisoff and Levine, 1969). The most plausible explanation for the value change in popular song lyrics is that changes in the organization of the music industry, mainly the demise of network radio, expanding markets, and an increase in the number of competing record companies enabled musicians to obtain the power to decide the content of the songs they would record.

\section{The Rise of "Progressive Rock"}

A long-standing tradition of industry self-censorship suffered perhaps its greatest defeat in the scramble for "psychedelic" recording artists during the early months of 1967 . Once every major record company jumped on the momentary bandwagon to sign popular local bands in San Francisco to recording contracts, a seller's market developed. Unprece- 
dented cash advances of up to $\$ 65,000$ to performing groups were reported by music critic Ralph Gleason (1969). Columbia Records reportedly invested $\$ 250,000$ simply to purchase the recording contract of Janis Joplin's group, Big Brother and the Holding Company, from another firm (Gleason, 1969). As the number of ex-folk and jazz musicians following their colleagues Bob Dylan, Simon and Garfunkel, and the Byrds into the world of rock music increased, the definition of what is permissible in the content of popular song lyrics broadened significantly. Whereas record companies formerly could dictate the material to be recorded by musicians under contract, they were now in the relatively powerless position of having to approve or veto material already recorded and available for mass distribution.

Once they had invested in these groups, the record companies undertook an extensive marketing campaign to realize a healthy return on their investment (Hirsch, 1969). Unexpected resistance was encountered initially, however, from Top 40 radio stations' program directors and retail record dealers. Retailers hesitated to order records by unknown groups unless they could be made familiar to consumers via air-play over local Top 40 stations. But program directors in many parts of the country viewed the "San Francisco sound" as unproven in its appeal to audiences outside of the West Coast and hesitated to add new records in this popular song style to their playlists. The problem of air-play was solved at this point by the adoption of the progressive rock format by FM stations in major cities across the country. This format, as it features primarily hit protest songs, appeals predominantly to upper-middle-class white teenagers and young adults. Most treatments of rock music in the popular press seem directed at these children's parents. They create a false impression in equating protest hits (one of several distinct popular song styles) with all popular hits and in confusing the class-based audience for protest hits with the total youth audience. Each of these inferences, as we have seen, is unwarranted and misleading. While we have located several youth subcultures insofar as popular song style preferences are concerned, we found no evidence for the existence of a single, unified teenage culture strong enough to overcome within-group class and racial differences.

\section{CONCLUSION}

This paper reviewed four sociological approaches to the study of popular culture and related each to changes in the content of popular song 
lyrics during the last twenty years. We examined the method of content analysis, the search for effects, the impact of technological change on mass media programming, and some consequences of organizational changes in an entertainment industry. The latter two perspectives help to explain the paradoxical research finding of radical changes in song lyrics, on the one hand, and the apparent indifference of the teenage audience toward all song meanings, on the other.

Conventional courtship themes in popular song lyrics have given way to less traditional messages about all areas of social life. This change is partly due to (a) the ascendance of performers over previously powerful industry censors, and (b) changes in communications technology which transformed the radio industry. There is no evidence that popular songs per se affect the attitudes and behavior of young people nor even that a majority of listeners are aware of what many consider to be the message of hit protest songs.

\section{NOTES}

1. Two excellent reviews of the literature and arguments on both sides may be found in Gans (1966) and Brown (1968). See also the excellent collection of essays gathered by Rosenberg and White (1957).

2. Bauer and Bauer (1960) and Gans (1966) present extensive reviews of the critical literature, though both attempt to discredit the critics' arguments (Coser, $1960)$. For much of the original source material, see the anthologies of Rosenberg and White (1957) and Jacobs (1961).

3. Ahab Publishing Co. (B.M.I.); Monument Records.

4. Gear Publishing Co. (ASCAP); Capital Records.

5. Publisher unknown; Mainstream Records.

6. Tree Publishing Co. (B.M.I.) Monument Records.

7. The image of a hypodermic needle to characterize a theory of powerful, one-way mass media "effects" was first suggested by Berelson et al. (1954).

\section{REFERENCES}

ARNHEIM, R. (1943) “ The world of the daytime serial," pp. 507-548 in P. Lazarsfeld and F. Stanton (eds.) Radio Research, 1942-1943. New York: Duell, Sloan \& Pearce.

AUSTER, D. (1954) "A content analysis of Little Orphan Annie." Social Problems 2: 26-33.

BAUER, R. A. and A. H. BAUER (1960) "American mass society and mass media." J. of Social Issues 16, 3: 3-66. 
BERELSON, B. R. and P. SALTER (1946) "An analysis of magazine fiction." Public Opinion Q. 10: 168-197.

BERELSON, B. R., P. LAZARSFELD, and W. McPHEE (1954) Voting. Chicago: Univ. of Chicago Press.

Billboard (1967) "Anti-smut McClendon to set up fringe panel." May 20: 1.

BROWN, R. L. (1968) "The creative process in the popular arts." International Social Science J. 20, 4: 613-624.

BRUNSWICK, A. (1962) "Popular taste in music as reflected by behavior with regard to phonograph records." Unpublished.

CAREY, T. (1969) "Changing courtship patterns in the popular song." Amer. J. of Sociology 74 (May): 720-731.

COLE, R. (1970) "Top songs in the sixties: a content analysis of popular lyrics." Research Division, School of Journalism and Mass Communication, University of Minnesota. (mimeo)

COLEMAN, J. S. (1961) The Adolescent Society. Glencoe: Free Press.

COSER, L. (1960) "Comments on Bauer and Bauer." J. of Social Issues 16, 3: 78-84.

DENISOFF, R. S. and M. H. LEVINE (1969) "The popular protest song: the case of the "eve of destruction.' " California State College. (working paper)

FRIEDRICH, O. (1969) "Killing the Saturday Evening Post." Harper's 239 (December): 92-121.

GANS, H. L. (1966) "Popular culture in America: social problem in a mass society or social asset in a pluralist society?" pp. 549-620 in H. S. Becker (ed.) Social Problems: A Modern Approach. New York: John Wiley.

-_-(1964) "The rise of the problem film." Social Problems 11, 4 (Spring): 327-336.

-- (1961) "Pluralist aesthetics and subcultural programming: a proposal for cultural democracy in the mass media." Studies in Public Communication 3: 28-35.

GLEASON, R. (1969) The Jefferson Airplane and the San Francisco Sound. New York: Ballantine.

HAYAKAWA, S. I. (1955) "Popular songs vs. the facts of life." Etc: A General Review of Semantics 12: 83-95.

HIRSCH, P. (1970) "The processing of fads and fashions by cultural industries: an organization set analysis." Presented at the 1970 Annual Meetings of the American Sociological Association. (mimeo)

-- (1969) The Structure of the Popular Music Industry. Ann Arbor: Survey Research Center, University of Michigan.

HORTON, T. (1957) "The dialogue of courtship in popular songs." Amer. J. of Sociology 62 (May): 569-578.

JACOBS, N. [ed] (n.d.) Culture for the Millions? Boston: Beacon Press.

JOHNS-HEINE, P. and H. H. GERTH (1949) "Values in mass periodical fiction, 1921-1940." Public Opinion Q. 13: 105-113.

KATZ, E. and P. LAZARSFELD (1955) Personal Influence. Glencoe: Free Press.

KRACAUER S. (1949) "National types as Hollywood presents them." Public Opinion Q. 13: 53-72.

LIPSET, S. M. and N. J. SMELSER [eds.] (1961) Sociology: The Progress of a Decade. Englewood Cliffs: Prentice-Hall. 
McLAUGHLIN, M.C. (1968) "The social world of American popular songs." Master's thesis, Department of Anthropology, Cornell University.

MERTON, R. K. (1936) "The unanticipated consequences of purposive social action." Amer. Soc. Rev. 1 : 894-904.

MOONEY, F. (1968) "Popular music since the 1920's: the significance of shifting taste." Amer. Q. 20: 68-85.

New York Times (1969) "Linkletter talks on drugs to Nixon." October 24: 18.

--- (1967) "Record industry turning to younger producers." September 13: 38.

OGBURN, W. F. (1964) On Culture and Social Change. O. D. Duncan (ed.) Chicago: Univ. of Chicago Press.

PEATMAN, J. (1944) "Radio and popular music," pp. 335-393, in P. Lazarsfeld and F. Stanton (eds.) Radio Research: 1942-1943. New York: Duell, Sloan \& Pearce.

PETERSON, A. and D. G. BERGER (1967) "The dollar and pap culture: the influence of changing industry structure on the control of social commentary in popular music." (Unpublished). Record Industry Association of America (1964)

Record Industry Association of America (1964) Radio and Records.

RIESMAN, D. (1954) "Listening to popular music," in B. Rosenberg and D. M. White [eds.] (1957) Mass Culture. Glencoe: Free Press.

ROBINSON, P. and P. M. HIRSCH (1969a) "Teenage response to rock and roll protest songs." Presented at the 1969 Annual Meetings of the American Sociological Association, San Francisco.

--- (1969b) "It's the sound that does it." Psychology Today 3 (October): 42-45.

ROSENBERG, B. and D. M. WHITE [eds.] (1957) Mass Culture. Glencoe: Free Press.

SCHUESSLER, K. (1948) "Social background and musical taste." Amer. Soc. Rev. 13: 330-335.

WOLFE, T. (1967) "The first tycoon of teen," in The Kandy-Kolored Tangerine Flake Streamline Baby. New York: Fauer, Strauss \& Giroux.

WOLFENSTEIN, M. and N. LEITES (1950) The Good-Bad Girl in Movies: A Psychological Study. New York: Free Press. 